\title{
Forecasting Inflation and Output: Comparing Data-Rich Models with Simple Rules
}

\author{
William T. Gavin and Kevin L. Kliesen
}

\begin{abstract}
There has been a resurgence of interest in dynamic factor models for use by policy advisors. Dynamic factor methods can be used to incorporate a wide range of economic information when forecasting or measuring economic shocks. This article introduces dynamic factor models that underlie the data-rich methods and also tests whether the data-rich models can help a benchmark autoregressive model forecast alternative measures of inflation and real economic activity at horizons of 3, 12, and 24 months ahead. The authors find that, over the past decade, the data-rich models significantly improve the forecasts for a variety of real output and inflation indicators. For all the series that they examine, the authors find that the data-rich models become more useful when forecasting over longer horizons. The exception is the unemployment rate, where the principal components provide significant forecasting information at all horizons. (JEL C32, C53, E31, E37)
\end{abstract}

Federal Reserve Bank of St. Louis Review, May/June 2008, 90(3, Part 1), pp. 175-92.

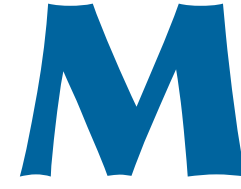

onetary policymakers focus on economic forecasts of a few key variables such as inflation, GDP, and the unemployment rate, but they look at many other variables when making these forecasts. In principle, information about other economic indicators should be useful in forecasting economic variables. A key problem is deciding which, if any, other series to include. Recent studies have shown that dynamic factor models may provide a parsimonious way to include incoming information about a wide variety of economic activity. These models use a large data set to extract a few common factors.

Many researchers, including Stock and Watson (1999, 2002), Bernanke and Boivin (2003), Bernanke, Boivin, and Eliasz (2005), and Giannone, Reichlin, and Sala (2005), have promoted the idea that dynamic factor models can be used to improve empirical macroeconomic analysis. Stock and Watson have instead focused on forecasting. Bernanke and coauthors introduced the term "data-rich environment" and have focused on applied policy models (structural vector autoregressions [VARs]).

The dynamic factor model has gained popularity for two important reasons. First, augmenting VARs with dynamic factors is a way to mitigate omitted variable bias in structural VARs. When Bernanke (1986) presented his first structural VAR model at a Carnegie-Rochester Public Policy Conference, King (1986) commented on the paper, noting that omitting any important macro variable from the policymaker's information set would result in incorrect inference about the effects of monetary policy. In small-dimension VARs, important variables are likely to be omitted. Giannone and Reichlin (2006) discuss the conditions under which using large data sets can help to identify economic structure.

The second reason for the dynamic factor model's popularity is that it provides a framework

William T. Gavin is a vice president and economist and Kevin L. Kliesen is an associate economist in the Research Division of the Federal Reserve Bank of St. Louis. The authors thank Marco Lippi and Dan Thornton for valuable comments and Michelle Armesto and Christopher J. Martinek for programming and research assistance.

(C) 2008, The Federal Reserve Bank of St. Louis. Articles may be reprinted, reproduced, published, distributed, displayed, and transmitted in their entirety if copyright notice, author name(s), and full citation are included. Abstracts, synopses, and other derivative works may be made only with prior written permission of the Federal Reserve Bank of St. Louis. 
for empirical analysis that is consistent with the stochastic structure of dynamic general equilibrium models. That is, these models determine a large number of variables with just a small number of structural shocks. A few shocks to preferences, technology, and policy drive all the macro variables. The empirical framework fits nicely with the theoretical framework. Evans and Marshall (2006) and Boivin and Giannoni (2006) use dynamic factor techniques to estimate the parameters and shocks of general equilibrium models.

The first part of the paper introduces the dynamic factor model framework. The second part of the paper uses a Granger causality framework to test whether the data-rich models make a statistically significant improvement in the benchmark autoregressive forecasts. ${ }^{1}$ To preview the results, we find that, for the past decade anyway, the data-rich framework provides additional information to significantly improve forecasts of inflation and real activity.

\section{INTRODUCTION TO DYNAMIC FACTOR MODELS}

To get a sense of how dynamic factor models incorporate large amounts of information, consider the makeup of the U.S. economy. As of March 2006, the U.S. economy included about 110 million households, with an average annual income of over $\$ 60,000$. There were almost 9 million establishments (firm locations) as derived from quarterly tax filings and reports to various state unemployment insurance programs. Government statistical agencies collect data about prices and spending by consumers and firms to create the various price indices and spending categories that are used in compiling the national income and product accounts.

Every day the decisions of these millions of households and firms are affected by common macroeconomic factors such as technology, tax rates, interest rates, and government spending. Shocks to these common factors, both good and bad, affect spending, productivity, and work

1 See Eickmeier and Ziegler (2006) for a survey of the large and growing literature on forecasting with dynamic factor models. effort. The common factors and shocks to them are pervasive, affecting every economic indicator. The decisions of households and firms are also affected by idiosyncratic shocks that are particular to individual firms and households. There are good idiosyncratic shocks such as births, strokes of genius, and opportunities taken. There are also bad idiosyncratic shocks such as death, sickness, accidents, and ideas that do not work out. In contrast to shocks to the common factors that affect everyone, like unexpected monetary policy actions or oil price increases, idiosyncratic shocks affect individuals or a particular market or economic sector.

Figure 1 illustrates the nature of the problem for the macroeconomist. In the center is the economy made up of households, firms, and government embedded in physical and institutional structures. To "map" the economy, private firms and public agencies collect an enormous amount of information that is organized and reported by various public and private sources. The most important of these economic indicators are gross domestic product (over $\$ 13.5$ trillion in 2007), inflation (the consumer price index [CPI] inflation trend has been rather steady around $2^{1 / 2}$ percent over the past decade), and the number of jobs (payroll employment was about 138 million at the end of 2007). These data are aggregated using thousands of bits of information coming from a sample of the households, firms, and government. In this paper we use a much smaller, yet very rich data set including 157 time series describing the evolution of production, employment, spending, inflation, interest rates, exchange rates, and asset prices. Incoming news about these time series informs us about the short-term stage of the business cycle and expected long-run trends for the major macroeconomic indicators.

On the left side of Figure 1 we sort the factors into those that are common to all the economic indicators and those that are idiosyncratic. The level of technology in science and industry, including management science, is a common factor. Recent innovations in computer technology have changed the way everyone keeps track of information and communicates with others. Other common factors include monetary and fiscal 
Figure 1

\section{Schematic for Data-Rich Models}

\section{A Few Common Factors}

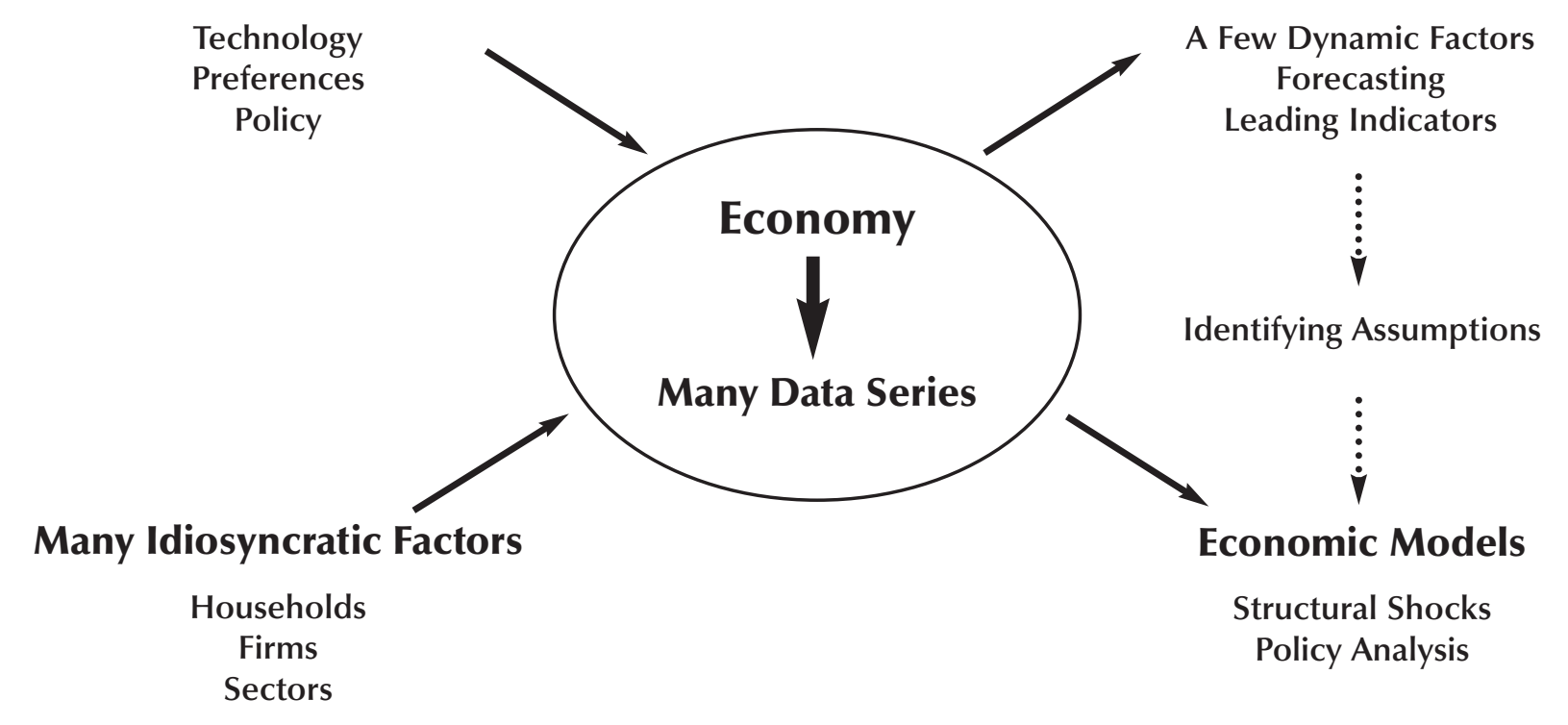

policy. Although more difficult to measure, shocks to household preferences for consumption and leisure may also appear to be economy-wide. Researchers want to measure these common factors and shocks to them because they help forecast inflation and output, but also because they are needed to understand how the economy workswhich is essential for evaluating the effects of past and proposed policies.

The key assumption underlying the dynamic factor model is that each of the economic indicators is assumed to be driven by a common component made up of a small number of common factors and an idiosyncratic component. Because each of the economic indicators represents the activities of many households and firms, the idiosyncratic shocks estimated in our model may share some common elements. We assume, however, that, unlike the shocks to the common factors, the idiosyncratic shocks do not have economywide effects.

On the top right side of Figure 1 we see that a dynamic factor model can be used to estimate a set of common factors that affect all economic time series. The dynamic factor model is designed to extract the small number of common factors from a large set of economic indicators. Stock and Watson (1989) developed coincident and leading indicators of the business cycle using dynamic factor methods. ${ }^{2}$ Stock and Watson (2002) also use this statistical model to make economic forecasts. Giannone, Reichlin, and Small (2005) have developed a dynamic factor model that is used by the Federal Reserve Board to make short-term forecasts for a large cross-section of data. The estimated common factors are reduced-form constructs-linear combinations of the structural factors that we would like to observe. On the bottom right side of Figure 1, we see that an economic model must be specified to identify the structural factors and the structural shocks that are of most interest to policymakers and policy advisors. Here we focus on using the information

2 The Federal Reserve Bank of Chicago maintains this leading indicator index. See Evans, Liu, and Pham-Kantor (2002). 


\section{Gavin and Kliesen}

in the common factors to forecast indicators of inflation and output.

The basic statistical tools used are principal component and factor analysis. ${ }^{3}$ We observe a large number of time series, $x_{i, t}, i=1,2, \ldots, n$; each is observed over $T$ periods. The key assumption in the factor model is that each of the individual $X_{i}$ 's can be decomposed into a small number of primitive factors that are common to all the $x$ 's and an idiosyncratic component, $e_{i, t}$, that is uncorrelated with the primitive factors:

$$
\begin{gathered}
x_{i t}=\lambda_{i}^{\prime} F_{t}+e_{i t}, \\
F_{t}=A(L) F_{t-1}+\varepsilon_{t}, \\
e_{i t}=\rho_{i}(L) e_{i t-1}+v_{t},
\end{gathered}
$$

where $F_{t}=\left(F_{1 t}, \ldots, F_{r t}\right)^{\prime}$ is a vector containing the $q$ common factors and

$$
A(L)=\sum_{j=0}^{P} A_{j} L^{j}
$$

is a polynomial in the lag operator, $L$. The time series $x_{i t}$ is related to the common factors by a vector of factor loadings, $\lambda_{i}=\left(\lambda_{i 1}, \ldots, \lambda_{i r}\right)^{\prime}$. The disturbance term in (1), $e_{i t}$, is the idiosyncratic component of $x_{i t}$, while $\lambda_{i}^{\prime} F_{t}$ is the common component. If the model is static then it is represented by equation (1). Dynamics may be introduced through the common factor component as in equation (2) and/or through the idiosyncratic component as in equation (3). Boivin and $\mathrm{Ng}$ (2005) discuss alternative methods that have been developed to estimate the factors and the factor loadings. ${ }^{4}$ Then they evaluate the forecasting performance of alternative methods of estimating the dynamic factors. For realistic assumptions about the data, they find that the best forecasting is a simple one that uses the large information set, but does not actually estimate the dynamic factors. We use this method, which involves two steps. The first step is to approximate the factors

3 For detailed development of these tools, see Forni et al. (2000) and Forni and Lippi (2001).

4 See also Schumacher (2007). Forni et al. (2005) find that using the generalized factor model of Forni et al. (2000) works well in a forecasting comparison with the approach we adopt here. using the $q$ largest principal components. ${ }^{5}$ The second step is to use these principal components in the forecasting model.

Our data matrix has 157 different monthly time series, which begin in January 1983 and end 300 months later in December 2007. ${ }^{6}$ In this particular case, the number of observations is larger than the number of cross-section units, although that need not be the case. One of the characteristics of this literature is that the number of primitive shocks is usually estimated to be small. Bai and $\mathrm{Ng}$ (2007a) estimate that there are more than two and perhaps as many as seven dynamic factors using the Stock and Watson (2005a) data set. Stock and Watson report a similar result using different methods. We start with a specification that encompasses the range of estimates of the number of factors.

\section{THE FORECASTING MODELS}

We evaluate the potential of estimated factors to improve economic forecasts by nesting them within a baseline autoregressive model. We begin with two simple models: a random walk model that predicts future performance at each horizon to be equal to the average performance over the previous 12 months and a univariate regression based on the past 12 months of the relevant variable.

The first model is from Atkeson and Ohanian (2001), who show that a random walk model could predict the year-ahead inflation rate better than the standard Phillips curve model. Stock and Watson (2005b) show that this better performance for the random walk model is particular to the most recent period of stable inflation and that their dynamic factor models (they used one with 157 economic indicators and another with just 61 real variables) could do as well as the random walk model even in the most recent period. Note that we use the past 12-month average inflation

\footnotetext{
5 Forni et al. (2000) derive conditions under which the largest principal components converge to the dynamic factors when there is weak correlation between $e_{i t}$ and $e_{j t}$ for $i \neq j$.

6 The set of information variables we use is similar to those used by Stock and Watson (2005a) and Bernanke, Boivin, and Eliasz (2005).
} 
rate as the forecast for the future-at all $h$ horizons, 3,12 , and 24 months. Hence, if the inflation rate for the 12 months ending in December 2007 was 4 percent, the random walk forecast for the average annual inflation rate over the following 3, 12, and 24 months would be 4 percent. The Atkeson and Ohanian (AO) model for the $h$-month-ahead inflation rate is given as

(4) ${ }_{A O} \pi_{t}^{h}=\frac{1}{12} \sum_{i=1}^{12} \pi_{t-i}+{ }_{A O} u_{t}^{h}$, where $\pi_{t}^{h}=\frac{1}{h} \sum_{i=0}^{h-1} \pi_{t+i}$

and $\pi$ is the inflation rate as measured by the change in the log of the price index and adjusted to be at an annual rate. The leading subscript $\mathrm{AO}$ indicates that this is the forecast and the forecast error for the AO model. The subscript $t$ and superscript $h$ indicate that this is the forecast for the average annual inflation rate for $h$ months beginning in month $t$.

The autoregressive models (AR) have the same dependent variable as above, but the weights on the 12 lags are estimated. ${ }^{7}$ For the $h$-month-ahead inflation forecast, the AR model is written as

$$
{ }_{A R} \pi_{t}^{h}=\phi_{0}+\sum_{i=1}^{12} \beta_{i} \pi_{t-i}+{ }_{A R} u_{t}^{h} .
$$

We use the same 12 lags for the various horizons and we do not search across lag length for the best in-sample fit when estimating the parameters of the forecasting model. ${ }^{8}$

The third set of models includes the datarich models (DRM). They use the largest principal components as estimates of the factors and add them to the AR model in equation (5) ${ }^{9}$ :

(6) ${ }_{D R M} \pi_{t}^{h}=\phi_{0}+\sum_{i=1}^{12} \beta_{i} \pi_{t-i}+\sum_{j=1}^{q} \sum_{k=1}^{m} P C_{j, t-k}+{ }_{D R M} u_{t}^{h}$.

\footnotetext{
7 Technically, these are not purely autoregressive models. We could have used an AR model of the 1-month-ahead inflation rate and then iterate over $h$ horizons. However, previous research suggests that forecasting the average over the forecast interval directly as we do here often works better than iterated forecasts in realistic (that is, relatively small) sample sizes.

${ }^{8}$ We used 12 lags to take account of seasonal regularities that remain in the data. Hansen (2008) provides theory and evidence to show that using information criteria to choose the best lag length in sample may result in choosing a model that does worst in out-ofsample prediction.
}

The model adds $m$ lags of the first $q$ estimated factors to the AR model. Based on the findings of Bai and Ng (2007a), we expect to find a relatively small number of primitive factors that will be spanned by a combination of primitive factors and their lags. However, in preliminary work for this study, we found that the best models sometimes had more factors and lags than suggested by tests for the number of primitive factors. Therefore, we run models with $q$ taking values from 1 to 7 and $m$ taking values from 1 to 12 . All the principal components enter the equation with the same lag length. Note that equation (6) is similar to the forecasting model used by Stock and Watson (2002).

\section{FORECASTING INFLATION}

In this section we report results from forecasting four measures of inflation: the CPI, the chain price index for personal consumption expenditures (PCEPI), and the two versions of these indices that exclude the prices of their food and energy components-that is, the core CPI and the core PCEPI. The CPI is the most common measure of inflation and it is commonly used to escalate wages and government benefits. It is also the concept that has been most commonly used as the policy objective by central banks that target inflation. In November 2007 the Federal Reserve began releasing quarterly projections of both total and core measures of PCEPI inflation. The PCEPI is used to compute real personal consumption expenditures in the national income and product accounts.

For our empirical analysis, we chose to begin in January 1983. Our rationale follows the work of those who find a structural break in many macroeconomic variables beginning around that time period. The structural break has been attributed to improved monetary policy, changes in the way firms manufacture and distribute goods, and good luck. ${ }^{10}$ The onset of this structural break is

9 See the appendix for a listing of the entire data set and the transformation used to standardize each variable.

${ }^{10}$ See, for example, Ahmed, Levin, and Wilson (2004), McConnell and Quiros (2000), or Taylor (1998). 


\section{Table 1}

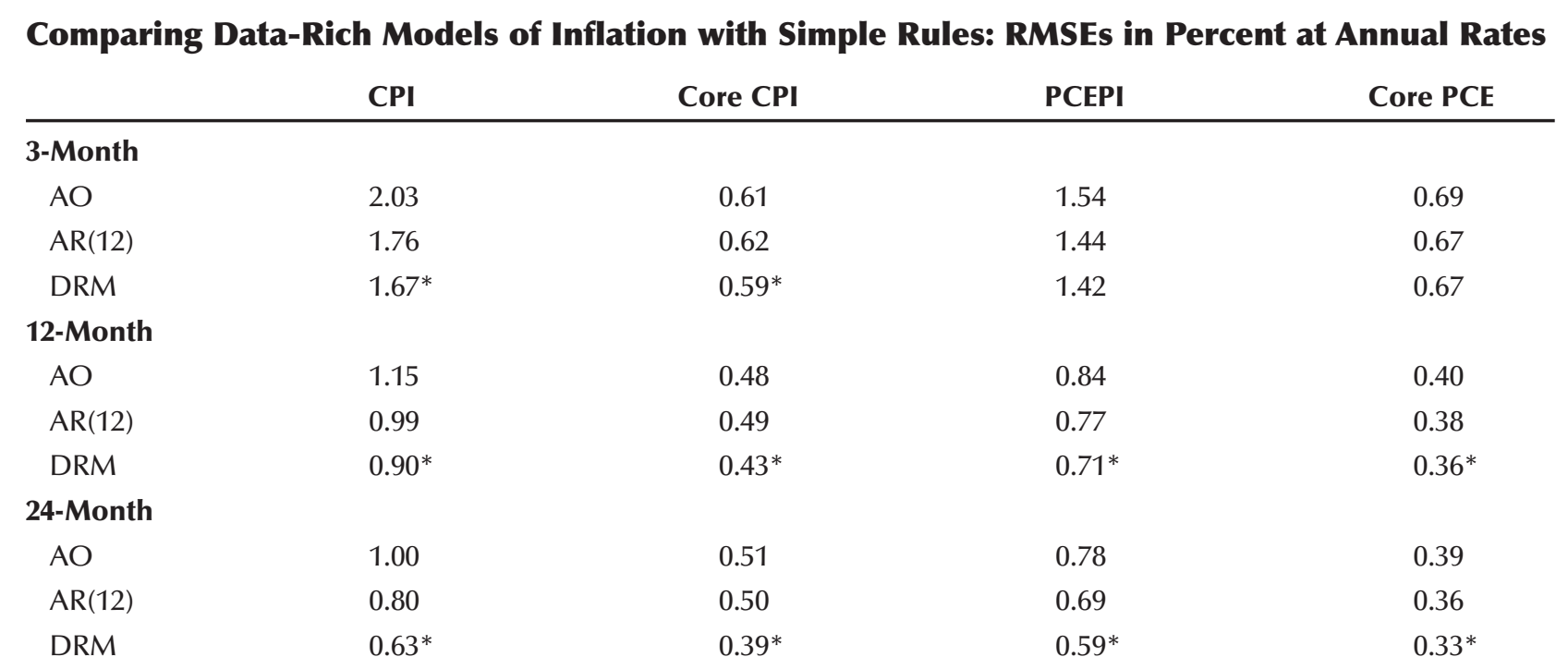

NOTE: *Rejects the null hypothesis that the factors do not Granger-cause the forecast variable at the 1 percent critical level.

usually termed the Great Moderation. In this data set we are using data through December 2007. Pseudo out-of-sample forecasts are produced for January 1997 using models that are estimated with the use of current vintage data. The models (and the principal components) are updated each month, producing recursive inflation forecasts with the final forecast period ending in September 2007. The beginning of the estimation period is fixed, so the number of observations used to estimate the forecasting equations grows over time. The dependent variable in each of the regressions is an average over the relevant forecast interval. The regressors enter as monthly variables.

\section{The Results}

The inflation forecasting results are shown in Table 1 and Figures 2 through 4 . The root mean squared errors (RMSEs) for the 3-month forecast horizon are shown in the top panel of Table 1. The first row reports the results for the AO model. This random walk model does a bit better than the AR model only for core CPI; but, even here, the difference is small. The baseline AR model is shown in the second row. The RMSE for the AR is substantially lower than the AO model for the all-item indices. The third row reports the RMSEs for the best DRMs. The inclusion of principal components significantly improves the forecasts for the CPI and its core measure, but it does not help forecast the PCEPI or the core PCEPI. ${ }^{11}$

Figure 2 shows the RMSEs from all the 3month-ahead inflation forecasts. (In Figures 2 through 7, the RMSE for the benchmark AR(12) is shown by the first bar and a gray horizontal line.) The best DRM for the CPI included three lags of seven principal components, a surprising profligate model with 33 estimated parameters. We also note that the models with 2 or 3 factors and 3 lags did almost as well and might be preferred on the principle of parsimony. That is, as fresh data arrive, one might have more confidence in using the smaller model that is less vulnerable to estimation error. In all the other cases, the best models were smaller, the core CPI and the PCEPI included just one principal component; and the best core PCEPI model included just one lag of

\footnotetext{
11 The asterisks in Tables 1 and 2 indicate that we can reject the hypothesis that the principal components do not help forecast at the 1 percent critical level using the McCracken (2007) out-ofsample test statistic.
} 


\section{Figure 2}

\section{Inflation Forecast Accuracy: RMSEs of 3-Month-Ahead Forecasts}
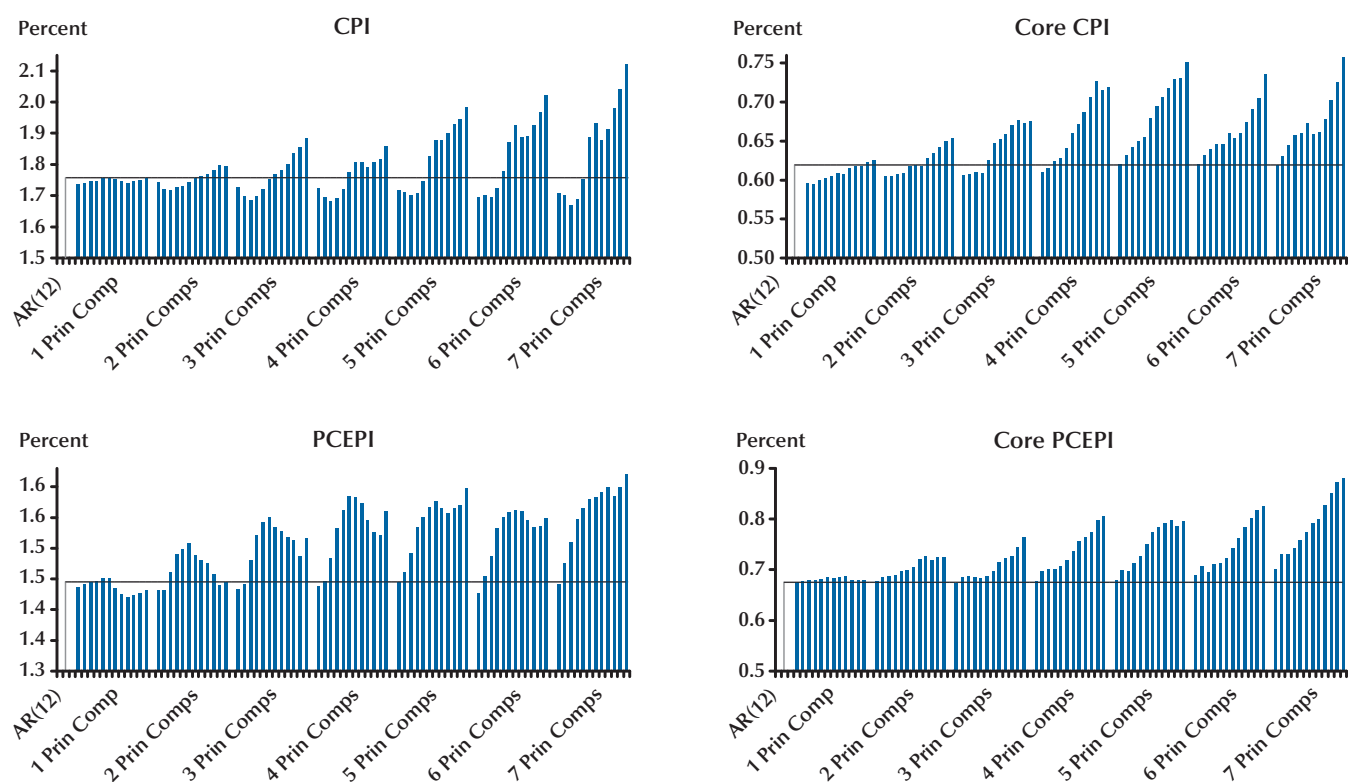

NOTE: Each group of principal components includes RMSEs from models with lags from 1 to 12.

\section{Figure 3}

Inflation Forecast Accuracy: RMSEs of 12-Month-Ahead Forecasts
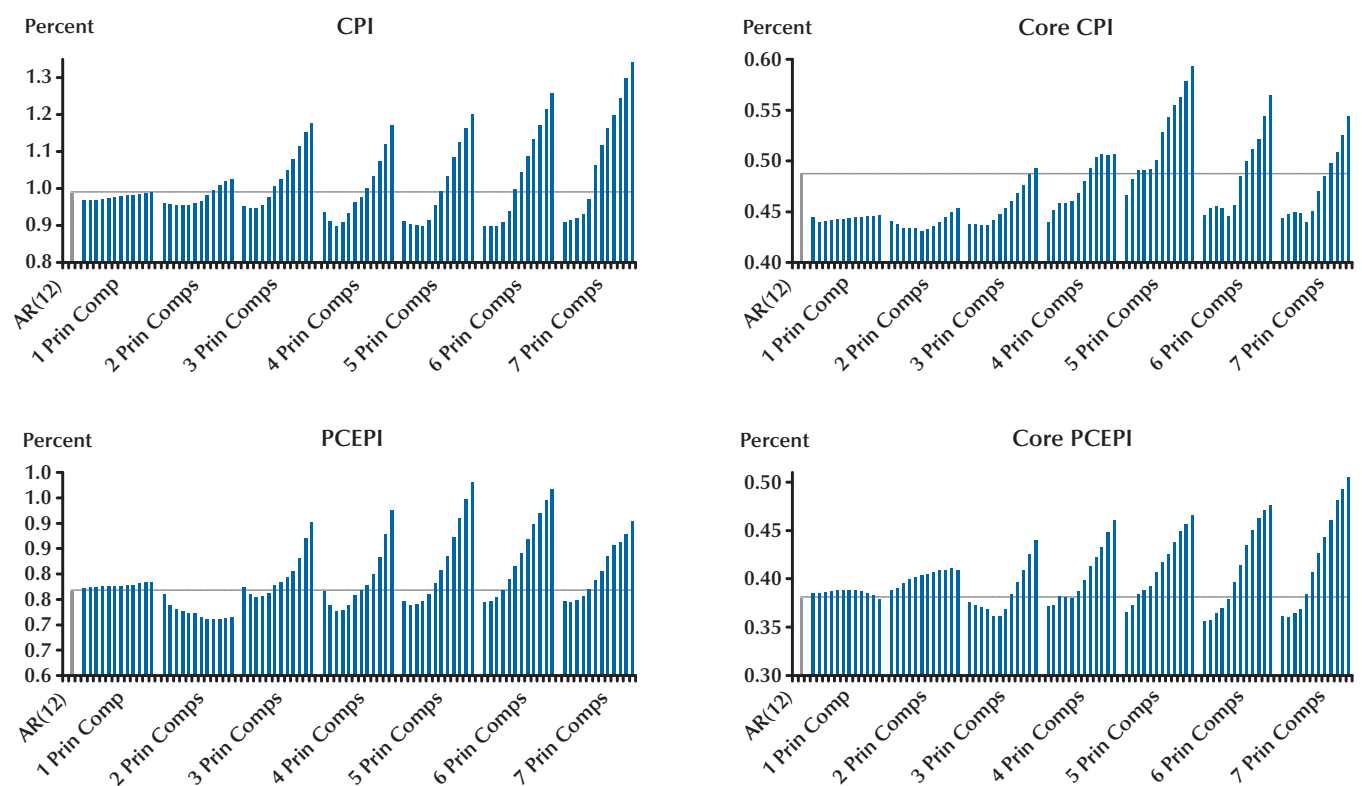

NOTE: Each group of principal components includes RMSEs from models with lags from 1 to 12 . 


\section{Figure 4}

\section{Inflation Forecast Accuracy: RMSEs of 24-Month-Ahead Forecasts}
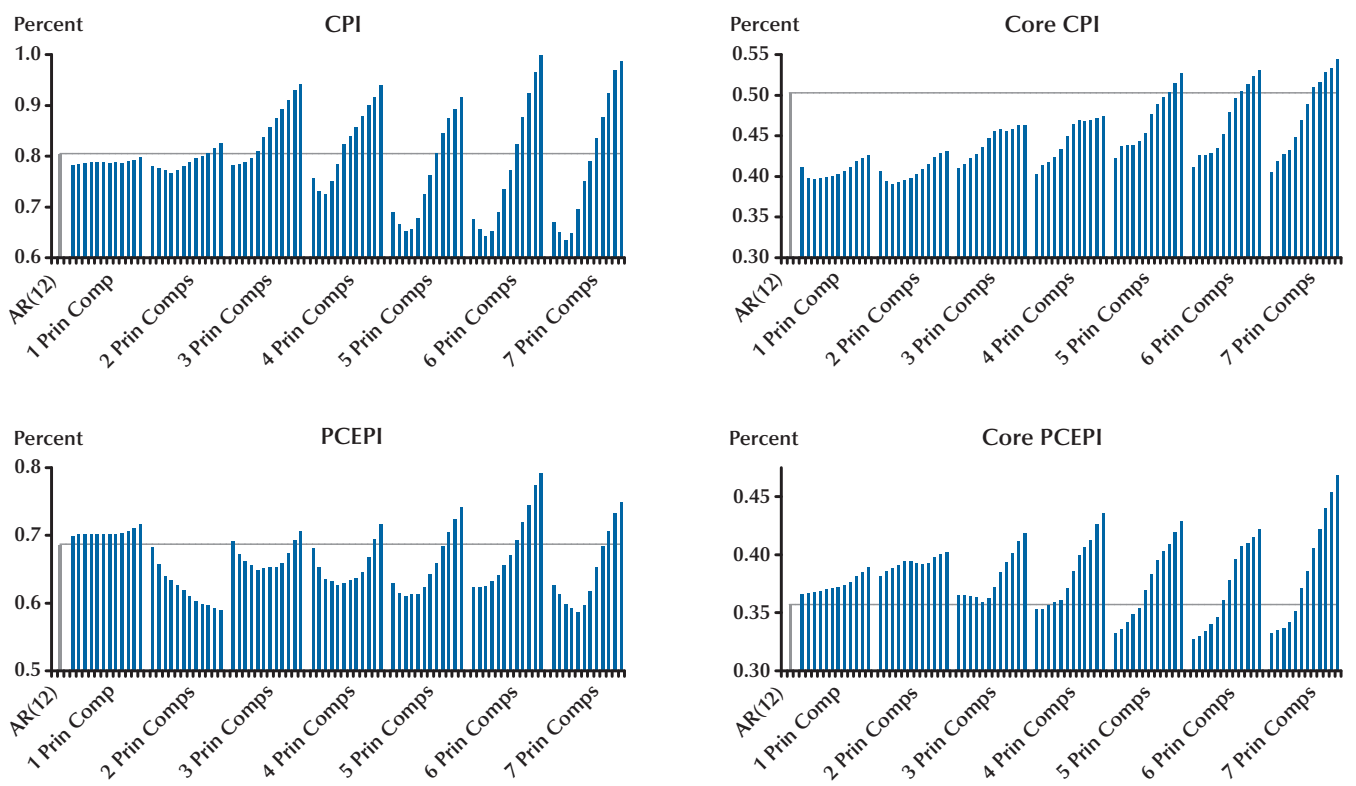

NOTE: Each group of principal components includes RMSEs from models with lags from 1 to 12.

Table 2

Comparing Data-Rich Models of Economic Activity with Simple Rules: RMSEs in Percent at Annual Rates for the Coincident Indicators and Real PCE

\begin{tabular}{|c|c|c|c|c|}
\hline & Coincident indicators & PMI & Real PCE & Unemployment rate \\
\hline \multicolumn{5}{|l|}{ 3-Month } \\
\hline $\mathrm{AO}$ & 1.65 & 4.21 & 2.19 & 0.070 \\
\hline $\mathrm{AR}(12)$ & 1.56 & 2.43 & 2.02 & 0.068 \\
\hline DRM & 1.55 & $2.32^{*}$ & 2.03 & $0.062^{*}$ \\
\hline \multicolumn{5}{|l|}{ 12-Month } \\
\hline $\mathrm{AO}$ & 1.54 & 4.94 & 1.17 & 0.055 \\
\hline $\mathrm{AR}(12)$ & 1.37 & 3.18 & 0.97 & 0.046 \\
\hline DRM & 1.36 & 3.14 & $0.92 *$ & $0.040^{*}$ \\
\hline \multicolumn{5}{|l|}{ 24-Month } \\
\hline $\mathrm{AO}$ & 1.71 & 4.86 & 1.19 & 0.058 \\
\hline $\mathrm{AR}(12)$ & 1.34 & 2.73 & 0.87 & 0.040 \\
\hline DRM & $1.22 *$ & $2.43^{*}$ & $0.61^{*}$ & $0.038^{*}$ \\
\hline
\end{tabular}

NOTE: *Rejects the null hypothesis that the factors do not Granger-cause the forecast variable at the 1 percent critical level. PMI is measured as the average level over the forecast horizon. The unemployment rate is measured as the average monthly change over the forecast horizon. 
the first three principal components. Figure 2 clearly shows that the DRMs did not contribute much to the 3-month forecasts for the PCEPI or its core measure.

The second panel in Table 1 reports the results for the 12-month-ahead inflation forecasts. Once again the AO model does better than the AR model only in the case of the core CPI. For all the other experiments reported in the paper, the AO model is worse than the AR model, which is usually worse than the model that is supplemented with the principal components. At the 12-month horizon, the information provided by the principal components is statistically significant at the 1 percent level for measures of inflation that we studied. Figure 3 shows that the DRMs do quite well when we extend the model to 12 months. For both measures of CPI inflation, the DRMs with 6 or 7 principal components did well, although the best model for the core CPI included just 2 principal components with 6 lags each. There was less improvement in the PCEPI and core PCEPI, but the improvement was statistically significant.

The bottom panel of Table 1 and Figure 4 report the results for the 24-month-ahead inflation forecasts. The results are similar to those for the 12-month forecasts, but the improvement in the forecasts over the benchmark AR model is larger. The principal components displayed significant information for all measures of inflation.

\section{FORECASTING REAL ACTIVITY}

Next, we use these models to forecast four monthly indicators of real economic activity: (i) the index of coincident indicators; (ii) the Purchasing Managers' Index (PMI), which is a diffusion index that measures activity in the manufacturing sector; (iii) real PCE; and (iv) the civilian unemployment rate. ${ }^{12}$ The index of coincident indicators and real personal consumption

\footnotetext{
${ }^{12}$ The coincident index is published by the Conference Board, and it is composed of (i) nonfarm payroll employment, (ii) industrial production, (iii) real manufacturing and trade sales, and (iv) real personal income less transfer payments. The Purchasing Managers' Index is published by the Institute for Supply Management.
}

expenditures are measured at annual growth rates, the ISM index is measured in levels, and the unemployment rate is measured as the first difference.

The results of the out-of sample forecasts for the real variables are presented in Table 2. The RMSEs of the random walk models are always the largest relative to the baseline AR and best DRM models. This result is not a surprise to macroeconomists and forecasters, but we report it to remind readers that the relatively good performance of the random walk model in forecasting inflation and asset prices does not carry over into measures of real economic activity. The top panel displays results for the 3-month forecast horizon. The principal components are statistically significant predictors of the PMI and unemployment rate. Figure 5 displays the RMSEs for the specifications of the DRMs of real activity at the 3-month horizon. The best DRM forecast for the PMI included 1 lag of the first 7 principal components. The best DRM forecast of the unemployment rate included just 1 lag of the first principal component, but all of the DRMs with a few lags did well in predicting the unemployment rate. Including the principal components did not help to forecast the index of coincident indicators or real PCE at the 3-month horizon.

The middle panel of Table 2 reports the results for the 12-month forecast. Figure 6 shows the RMSEs for the specifications of the DRMs of real activity at the 12-month horizon. The best model for the index of coincident indicators has 4 principal components with 9 lags but is no better than the benchmark AR model. The best model for the PMI was the DRM with 4 principal components and 1 lag; but, as with the coincident indicators, the principal components do not significantly improve the forecasts. The improvements in the forecasts of real PCE growth and the unemployment rate are statistically significant. Again, the best DRM of the unemployment rate includes just the first principal components, but now includes all 12 lags rather than just the first.

The bottom panel in Table 2 and Figure 7 report results for the 24-month forecasts of real economic indicators. The best DRM for each of the variables is significantly better than the bench- 


\section{Figure 5}

\section{Economic Activity Forecast Accuracy: RMSEs of 3-Month-Ahead Forecasts}
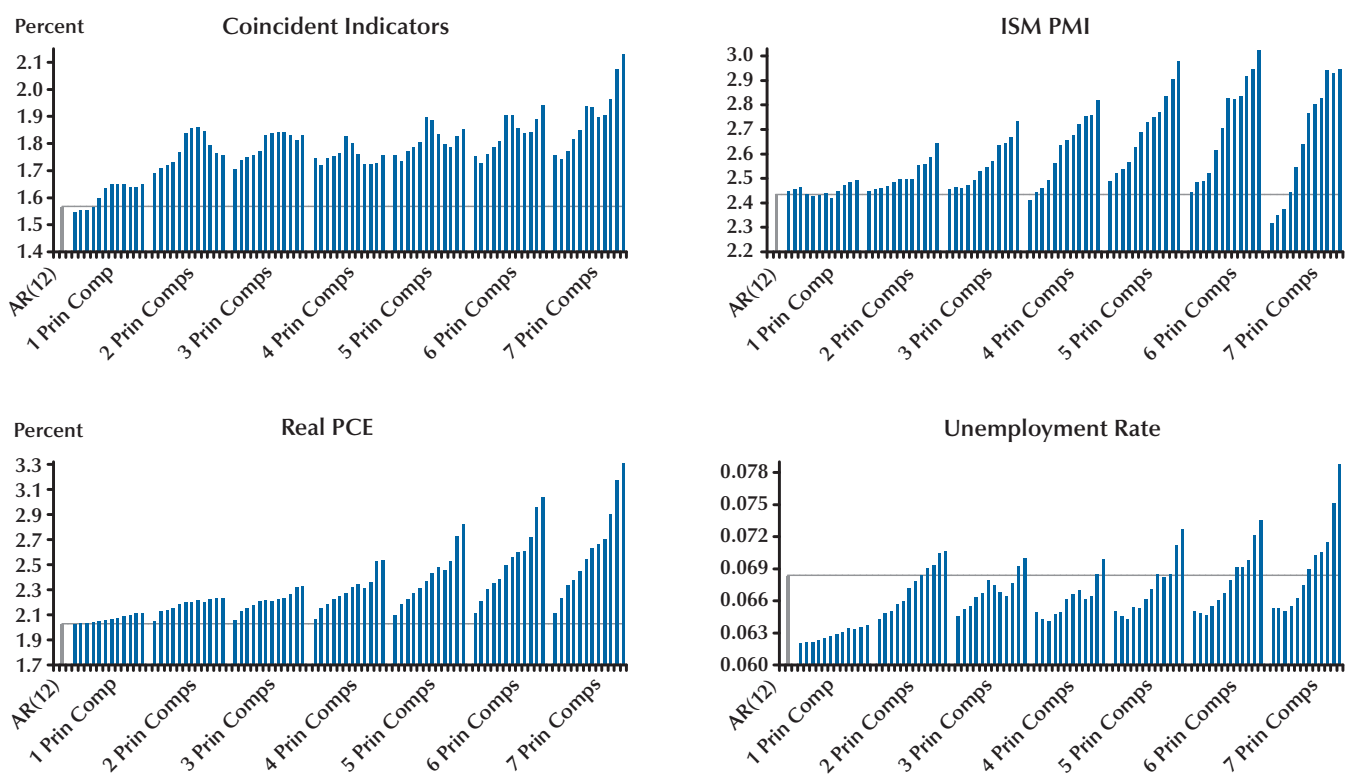

NOTE: Each group of principal components includes RMSEs from models with lags from 1 to 12 .

\section{Figure 6}

\section{Economic Activity Forecast Accuracy: RMSEs of 12-Month-Ahead Forecasts}
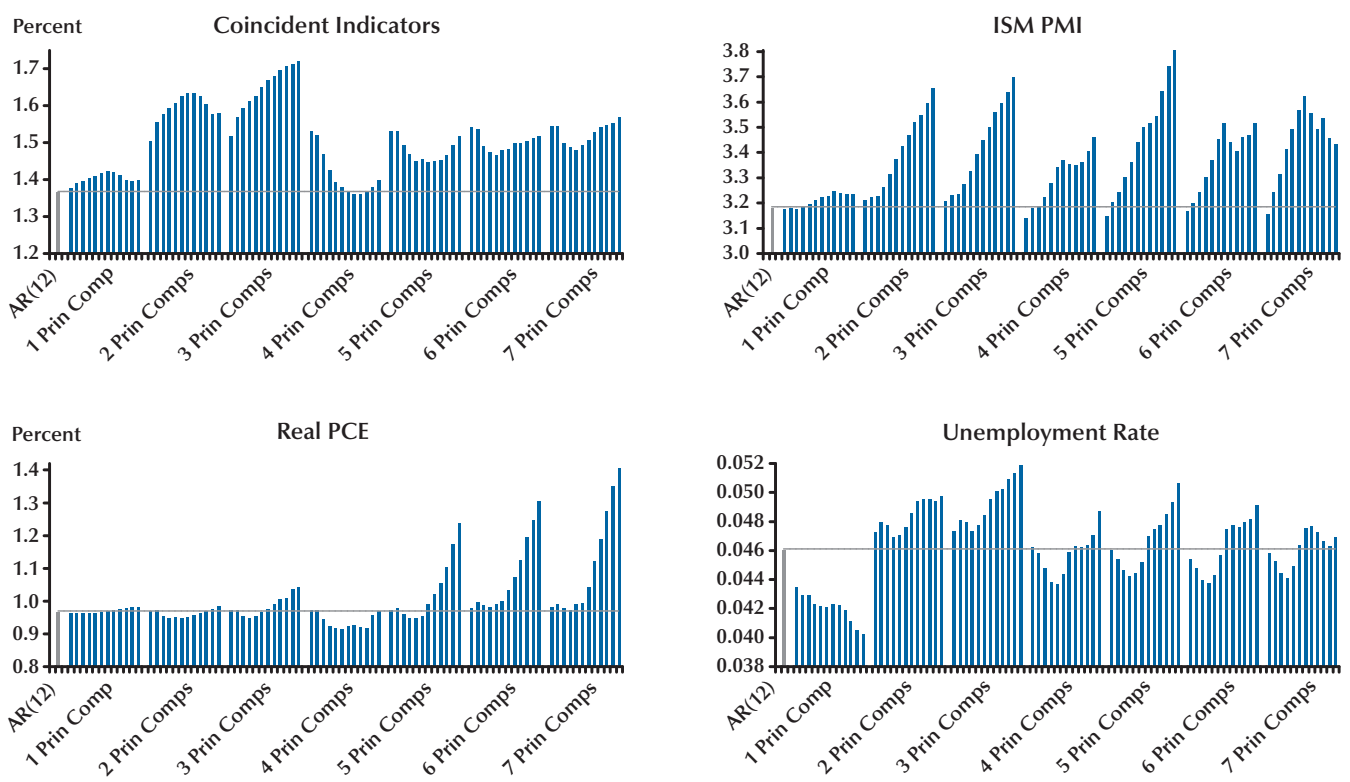

NOTE: Each group of principal components includes RMSEs from models with lags from 1 to 12 . 


\section{Figure 7}

\section{Economic Activity Forecast Accuracy: RMSEs of 24-Month-Ahead Forecasts}
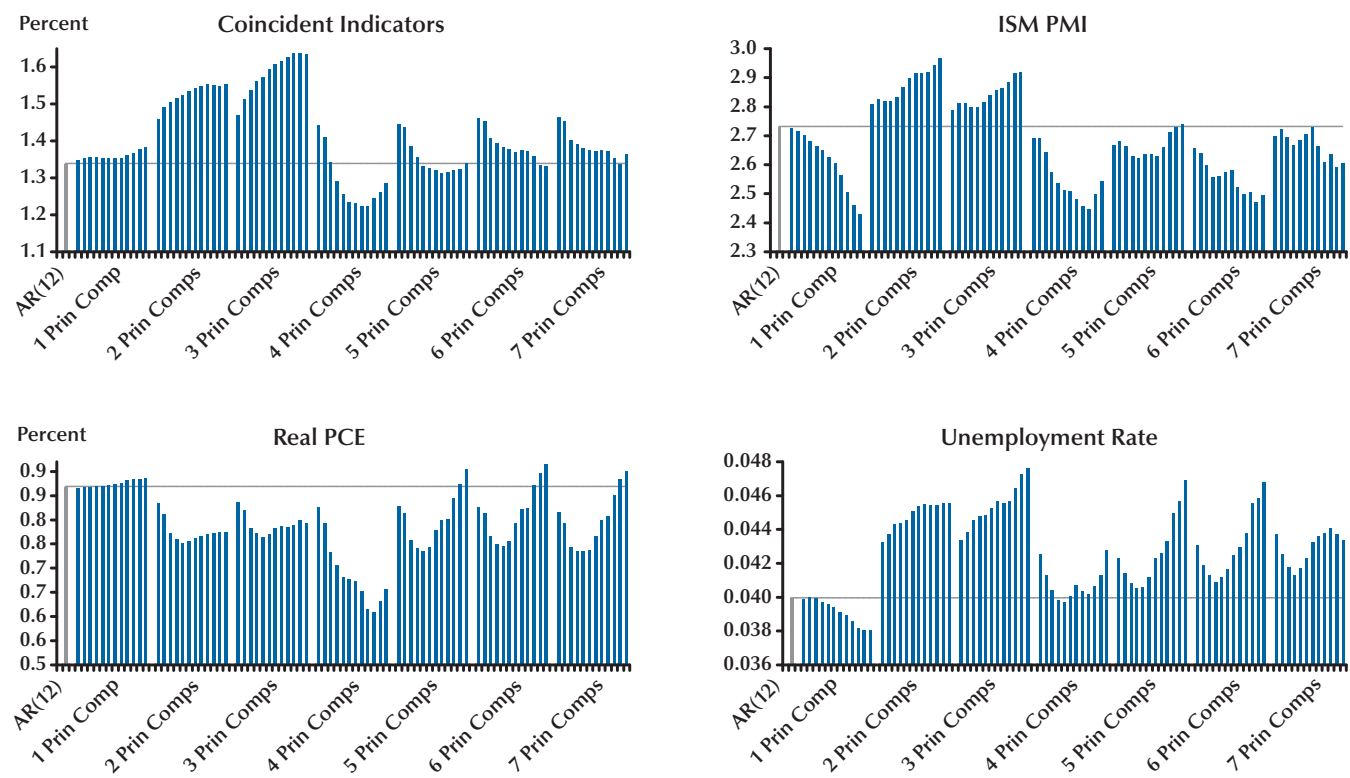

NOTE: Each group of principal components includes RMSEs from models with lags from 1 to 12.

mark AR model. The pattern in the RMSEs for the index of coincident indicators is similar to the pattern in the 12-month results, but the forecasts are better relative to the benchmark AR model. There is a substantial improvement in the PMI and real PCE forecasts relative to the 12month results. In both cases, the models with 4 lags and 8 to 10 lags do well. The 24-month unemployment rate models were a bit of an exception in that including more than 1 principal component usually made the DRM model produce a RMSE that was larger than the benchmark AR model. The results for the best out-of-sample forecasting version of equation (6) are summarized in Table 3.

\section{CONCLUSION}

In this paper we report the results of a simulated out-of-sample forecasting experiment in which we compared 85 models for each of eight economic indicators over three forecasting hori- zons (for a total of 2,040 models). The models were estimated over a period beginning in January 1983 and ending 2 months before the beginning of the forecast interval. We made 132 forecasts beginning in January 1997 and ending in December 2007. Generally, we find that the data-rich models can be used to improve forecasts of inflation and output. We found that using principal components to estimate the underlying common factors was useful in forecasting the CPI and its core measure at the 3-month horizon and all measures of inflation at the 12- and 24-month horizons. The factor methods were also helpful in predicting real variables. The data-rich models were useful in predicting the unemployment rate over all horizons and all the real variables over 24-month horizons.

In future research, we intend to apply these results in a real-time forecasting process. In some sense, our discovery of models that are more profligate than suggested by Bai and Ng (2007a) may be the result of data-mining in a specific 10- 
Table 3

What's the Best Data-Rich Model

\begin{tabular}{|c|c|c|c|c|c|}
\hline \multicolumn{3}{|c|}{ Inflation } & \multicolumn{3}{|c|}{ Real activity } \\
\hline & $q^{*}$ & $m$ & & $q$ & $m$ \\
\hline \multicolumn{6}{|c|}{ 3-Month-ahead forecasts } \\
\hline CPI & 7 & 3 & Coincident indicators & 1 & 1 \\
\hline Core CPI & 1 & 2 & ISM PMI & 7 & 1 \\
\hline PCEPI & 1 & 9 & Real PCE & 1 & 1 \\
\hline Core PCEPI & 3 & 1 & Unemployment rate & 1 & 1 \\
\hline \multicolumn{6}{|c|}{ 12-Month-ahead forecasts } \\
\hline $\mathrm{CPI}$ & 6 & 1 & Coincident indicators & 4 & 9 \\
\hline Core CPI & 2 & 6 & ISM PMI & 4 & 1 \\
\hline PCEPI & 2 & 9 & Real PCE & 4 & 6 \\
\hline Core PCEPI & 6 & 1 & Unemployment rate & 1 & 12 \\
\hline \multicolumn{6}{|c|}{ 24-Month-ahead forecasts } \\
\hline $\mathrm{CPI}$ & 7 & 3 & Coincident indicators & 4 & 8 \\
\hline Core CPI & 2 & 3 & ISM PMI & 1 & 12 \\
\hline PCEPI & 7 & 5 & Real PCE & 4 & 10 \\
\hline Core PCEPI & 6 & 1 & Unemployment rate & 1 & 12 \\
\hline
\end{tabular}

year sample. We are using out-of-sample forecast accuracy as a criterion for choosing which model is "best." We have not, however, applied these results in a recursive real-time forecasting application. We are confident, however, that there is persistence in the relative performance of the preferred specification that may prove useful in such an exercise. In this paper, we used a relatively unrestricted method that did not separately identify the common and idiosyncratic factors. In future research, we plan to identify the common factors and the factor loadings so that we can map the source of the information that improves forecast accuracy. We also plan to investigate the benefits of using procedures recommended in Bai and $\mathrm{Ng}$ (2007b) for choosing fewer, but informative predictors. They find that one can improve forecast accuracy by using such procedures for each specific variables at each specific forecasting horizon. We are also interested in using dynamic factor methods in combination with economic theory to identify structural economic shocks.
This is an emerging area of research that holds promise for analyzing policy.

\section{REFERENCES}

Atkeson, Andrew and Ohanian, Lee E. "Are Phillips Curves Useful for Forecasting Inflation?” Federal Reserve Bank of Minneapolis Quarterly Review, Winter 2001, 25(1), pp. 2-11.

Ahmed, Shagil; Levin, Andrew and Wilson, Beth Anne. "Recent U.S. Macroeconomic Stability: Good Policies, Good Practices, or Good Luck?" Review of Economics and Statistics, August 2004, 86(3), pp. 824-32.

Bai, Jushan and Ng, Serena. "Determining the Number of Primitive Shocks in Factor Models." Journal of Business and Economic Statistics, January 2007a, 25(1), pp. 52-60.

Bai, Jushan and Ng, Serena. "Forecasting Economic Time Series Using Targeted Predictors.” Working 
paper, University of Michigan, November 14, 2007b; forthcoming in Journal of Econometrics.

Bernanke Ben S. "Alternative Explanations of the Money-Income Correlation.” Carnegie-Rochester Conference Series on Public Policy, 1986, 25, pp. 49-100.

Bernanke, Ben S. and Boivin, Jean. "Monetary Policy in a Data-Rich Environment." Journal of Monetary Economics, April 2003, 50(3), pp. 525-46.

Bernanke, Ben; Boivin, Jean and Eliasz, Piotr. "Measuring the Effects of Monetary Policy: A Factor-Augmented Vector Autoregressive (FAVAR) Approach." Quarterly Journal of Economics, February 2005, 120(1), pp. 387-422.

Boivin, Jean and Giannoni, Marc P. "DSGE Models in a Data-Rich Environment." Presented at the Macro Seminar Series at the Federal Reserve Bank of St. Louis, July 6, 2006.

Boivin, Jean and Ng, Serena. "Understanding and Comparing Factor-Based Forecasts" International Journal of Central Banking, December 2005, 1, pp. 117-49.

Eickmeier, Sandra and Ziegler, Christina. "How Good Are Dynamic Factor Models at Forecasting Output and Inflation? A Meta-Analytic Approach.” Discussion Paper Series 2006-42, Deutsche Bundesbank, 2006.

Evans, Charles L.; Liu, Chin Te and Pham-Kanter, Genevieve. "The 2001 Recession and the Chicago Fed National Activity Index: Identifying Cycle Turning Points.” Federal Reserve Bank of Chicago Economic Perspectives, Third Quarter 2002, pp. 26-43.

Evans, Charles L. and Marshall, David A. "Fundamental Economic Shocks and the Macroeconomy." Unpublished manuscript, Federal Reserve Bank of Chicago, October 15, 2006.

Forni, Mario; Hallin, Marc; Lippi, Marco and Reichlin, Lucrezia. "The Generalized Dynamic-Factor Model: Identification and Estimation." Review of Economics and Statistics, November 2000, 82(4), pp. 540-54.
Forni, Mario; Hallin, Marc; Lippi, Marco and Reichlin, Lucrezia. "The Generalized Dynamic-Factor Model: One-Sided Estimation and Forecasting." Journal of the American Statistical Association, September 2005, 100(471), pp. 830-40.

Forni, Mario and Lippi, Marco. "The Generalized Dynamic Factor Model: Representation Theory." Econometric Theory, December 2001, 17(6), pp. 1113-41.

Giannone, Domenica and Reichlin, Lucrezia. "Does Information Help Recovering Structural Shocks From Past Observations?" Working Paper Series No. 632, European Central Bank, May 2006.

Giannone, Domenico; Reichlin, Lucrezia and Sala, Luca. "Monetary Policy in Real Time," in Mark Gertler and Kenneth Rogoff, eds., NBER Macroeconomics Annual 2004. Cambridge, MA: MIT Press, 2005, pp. 161-200.

Giannone, Domenico; Reichlin, Lucrezia and Small, David. "Nowcasting: The Real Time Informational Content of Macroeconomic Data Releases." 2005; http://homepages.ulb.ac.be/ dgiannon/Nowcasting. pdf; forthcoming in Journal of Monetary Economics.

Hansen, Peter R. "In-Sample and Out-of-Sample Fit: Their Joint Distribution and Its Implications for Model Selection and Model Averaging." Working Paper, Stanford University, March 18, 2008.

King, Robert G. "Money and Business Cycles: Comments on Bernanke and Related Literature." Carnegie-Rochester Conference Series on Public Policy, 1986, 25, pp. 101-16.

McConnell, Margaret M. and Perez Quiros, Gabriel. "Output Fluctuations in the United States: What Has Changed Since the Early 1980's?" American Economic Review, 2000, 90(5), pp. 1464-76.

McCracken, Michael W. "Asymptotics for Out-ofSample Tests of Granger Causality.” Journal of Econometrics, October 2007, 140, pp. 719-52.

Schumacher, Christian. "Forecasting German GDP Using Alternative Factor Models Based on Large Datasets." Journal of Forecasting, July 2007, 26(4), pp. 271-302. 


\section{Gavin and Kliesen}

Stock, James H. and Watson, Mark W. "New Indexes of Coincident and Leading Economic Indicators." NBER Macroeconomics Annual 1988, Cambridge, MA: MIT Press, 1989, pp. 351-93.

Stock, James H. and Watson, Mark W. "Forecasting Inflation." Journal of Monetary Economics, October 1999, 44(2), pp. 293-335.

Stock, James H. and Watson, Mark W. "Macroeconomic Forecasting Using Diffusion Indexes." Journal of Business and Economic Statistics, April 2002, 20(2), pp. 147-62.

Stock, James H. and Watson, Mark W. "Implications of Dynamic Factor Models for VAR Analysis."
NBER Working Paper 11467, National Bureau of Economic Research, 2005a.

Stock, James H. and Watson, Mark W. "Has Inflation Become Harder to Forecast?" Presented at the conference "Quantitative Evidence on Price Determination," September 29-30, 2005b, Board of Governors of the Federal Reserve System, Washington, DC.

Taylor, John. "Monetary Policy and the Long Boom." Federal Reserve Bank of St. Louis Review, November/December 1998, 80(6), pp. 3-11.

\section{APPENDIX}

\section{Data Used in the DFM Analysis, Their Transformation, and Their Source}

\begin{tabular}{|c|c|c|}
\hline Description & Transformation & Source \\
\hline \multicolumn{3}{|l|}{ Real Output and Income } \\
\hline 1 IP: Total Index $(\mathrm{SA}, 2002=100)$ & DLN & FRB \\
\hline 2 IP: Final Products and Nonindustrial Supplies (SA, $2002=100)$ & DLN & FRB \\
\hline 3 IP: Final Products $\{$ Mkt Group $\}(S A, 2002=100)$ & DLN & FRB \\
\hline 4 IP: Consumer Goods (SA, $2002=100)$ & DLN & FRB \\
\hline 5 IP: Durable Consumer Goods $(S A, 2002=100)$ & DLN & FRB \\
\hline 6 IP: Nondurable Consumer Goods $(S A, 2002=100)$ & DLN & FRB \\
\hline 7 IP: Business Equipment $(S A, 2002=100)$ & DLN & FRB \\
\hline 8 IP: Materials $(S A, 2002=100)$ & DLN & FRB \\
\hline 9 IP: Durable Materials $(S A, 2002=100)$ & DLN & FRB \\
\hline 10 IP: Nondurable Materials $(S A, 2002=100)$ & DLN & FRB \\
\hline 11 IP: Manufacturing $(\mathrm{SIC})(\mathrm{SA}, 2002=100)$ & DLN & FRB \\
\hline 12 IP: Durable Mfg [NAICS] (SA, $2002=100)$ & DLN & FRB \\
\hline 13 IP: Nonindustrial Supplies $(S A, 2002=100)$ & DLN & FRB \\
\hline 14 IP: Nondurable Mfg [NAICS] (SA, $2002=100)$ & DLN & FRB \\
\hline 15 Industrial Production: Mining $(S A, 2002=100)$ & DLN & FRB \\
\hline 16 IP: Consumer Energy Products: Residential Utilities (SA, $2002=100)$ & DLN & FRB \\
\hline 17 IP: Consumer Energy Products: Fuels $(S A, 2002=100)$ & DLN & FRB \\
\hline 18 IP: Electric and Gas Utilities $(\mathrm{SA}, 2002=100)$ & DLN & FRB \\
\hline 19 IP: Motor Vehicle Assemblies (SAAR, Mil.Units) & DLN & FRB \\
\hline 20 ISM Mfg: Production Index (SA, 50+ = Econ Expand) & LV & ISM \\
\hline 21 Capacity Utilization: Mfg [SIC] (SA, \% of Capacity) & DLV & FRB \\
\hline 22 Real Personal Income (SAAR, Bil.Chn.2000\$) & DLN & $\mathrm{BEA} / \mathrm{H}$ \\
\hline
\end{tabular}


Gavin and Kliesen

Description

23 Real Personal Income Less Transfer Payments (SAAR, Bil.Chn.2000\$)

24 Real Disposable Personal Income (SAAR, Bil.Chn.2000\$)

\section{Employment and Hours}

25 Index of Help-Wanted Advertising in Newspapers (SA, $1987=100$ )

26 Ratio: Help-Wanted Advertising in Newspapers/Number Unemployed (SA)

27 Civilian Employment: Sixteen Years \& Over (SA, Thous.)

28 Civilian Employment: Nonagricultural Industries: 16 yr + (SA, Thous.)

29 Civilian Unemployment Rate: 16 yr + (SA, \%)

30 Civilian Unemployment Rate: Men, 25-54 Years (SA, \%)

31 Average \{Mean\} Duration of Unemployment (SA, Weeks)

32 Civilians Unemployed for Less Than 5 Weeks (SA, Thous.)

33 Civilians Unemployed for 5-14 Weeks (SA, Thous.)

34 Civilians Unemployed for 15 Weeks and Over (SA, Thous.)

35 Civilians Unemployed for 15-26 Weeks (SA, Thous.)

36 Civilians Unemployed for 27 Weeks and Over (SA, Thous.)

37 Unemployment Insurance: Initial Claims, State Programs (SA, Thous.)

38 All Employees: Total Nonfarm (SA, Thous.)

39 All Employees: Total Private Industries (SA, Thous.)

40 All Employees: Goods-producing Industries (SA, Thous.)

41 All Employees: Mining (SA, Thous.)

42 All Employees: Construction (SA, Thous.)

43 All Employees: Mfg (SA, Thous.)

44 All Employees: Durable Goods Mfg (SA, Thous.)

45 All Employees: Nondurable Goods Mfg (SA, Thous.)

46 All Employees: Service-providing Industries (SA, Thous.)

47 All Employees: Trade, Transportation \& Utilities (SA, Thous.)

48 All Employees: Wholesale Trade (SA, Thous.)

49 All Employees: Retail Trade (SA, Thous.)

50 All Employees: Financial Activities (SA, Thous.)

51 All Employees: Government (SA, Thous.)

52 Aggregate Weekly Hours Index: Total Private Industries (SA, $2002=100$ )

53 Average Weekly Hours: Goods-producing Industries (SA, Hrs)

54 Average Weekly Hours: Overtime: Mfg (SA, Hrs)

55 Average Weekly Hours: Mfg (SA, Hrs)

56 ISM Mfg: Employment Index (SA, 50+ = Econ Expand)

Real Retail, Manufacturing, and Trade Sales

57 Mfg \& Trade Sales (SA, Mil.Chn.2000\$)

58 Mfg \& Trade Inventories (EOP, SA, Bil.Chn.2000\$)

59 Mfg \& Trade: Inventories/Sales Ratio (SA, Chn.2000\$)

60 Mfrs Shipments of Mobile Homes (SAAR, Thous.Units)

61 Real Retail Sales \& Food Services

Inventories and Orders

62 ISM Mfg: Inventories Index (SA, 50+ = Econ Expand)
Transformation

$\begin{array}{cc}\text { DLN } & \text { BEA/H } \\ \text { DLN } & \text { BEA }\end{array}$

DLN

CNFBOARD

DLN $\mathrm{CB} / \mathrm{BLS} / \mathrm{H}$

DLN

BLS

DLN

BLS

DLV

BLS

DLV

BLS

DLV

BLS

DLN

BLS

DLN

BLS

DLN

BLS

DLN

BLS

DLN

BLS

DLV

DOL

DLN

BLS

DLN

BLS

DLN

BLS

DLN

DLN

BLS

DLN

BLS

DLN

BLS

DLN

DLN

DLN

DLN

DLN

DLN

DLN

DLN

LV

DLV

DLV

LV

DLN

DLN

DLN

LN

DLN

LV

ISM 


\section{Gavin and Kliesen}

Description

63 ISM Mfg: New Orders Index (SA, 50+ = Econ Expand)

64 Mfrs New Orders: Durable Goods (SA, Mil.Chn.2000\$)

65 Mfrs New Orders: Nondefense Capital Goods (SA, Mil.1982\$)

66 Mfrs Unfilled Orders: Durable Goods (SA, EOP, Mil.Chn.2000\$)

\section{Consumption}

67 Real Personal Consumption Expenditures: Durable Goods (SAAR, Bil.Chn.2000\$)

68 Real Personal Consumption Expenditures: Nondurable Goods (SAAR, Bil.Chn.2000\$)

69 Real Personal Consumption Expenditures: Services (SAAR, Bil.Chn.2000\$)

70 Real Personal Consumption Expenditures (SAAR, Bil.Chn.2000\$)

\section{Housing Starts and Sales}

71 Housing Starts (SAAR, Thous.Units)

72 Housing Starts: Northeast (SAAR, Thous.Units)

73 Housing Starts: Midwest (SAAR, Thous.Units)

74 Housing Starts: South (SAAR, Thous.Units)

75 Housing Starts: West (SAAR, Thous.Units)

76 New Pvt Housing Units Authorized by Building Permit (SAAR, Thous.Units)

77 Housing Units Authorized by Permit: Northeast (SAAR, Thous.Units)

78 Housing Units Authorized by Permit: Midwest (SAAR, Thous.Units)

79 Housing Units Authorized by Permit: South (SAAR, Thous.Units)

80 Housing Units Authorized by Permit: West (SAAR, Thous.Units)

81 Total Public Construction (SAAR, Mil.Chn.1996\$)

82 Private Construction: Nonresidential (SAAR, Mil.Chan.1996\$)

\section{Stock Prices}

83 Stock Price Index: S\&P 500 Composite $(1941-43=10)$

84 Stock Price Index: S\&P 500 Industrials $(1941-43=10)$

85 S\&P 500 Composite, Dividend Yield (\%)

86 S\&P 500 Composite, P/E Ratio, 4-Qtr Trailing Earnings (Ratio)

87 Stock Price Index: NASDAQ Composite (Feb-5-71 = 100)

\section{Exchange Rates}

88 Nominal Broad Trade-Weighted Exchange Value of the US\$ (Jan-97 = 100)

89 Real Broad Trade-Weighted Exchange Value of the US\$ (Mar-73 =100)

90 Foreign Exchange Rate: Switzerland (Franc/US\$)

91 Foreign Exchange Rate: Japan (Yen/US\$)

92 Foreign Exchange Rate: United Kingdom (US\$/Pound)

93 Foreign Exchange Rate: Canada (C\$/US\$)

\section{Interest Rates}

94 Federal Funds [effective] Rate (\% per annum)

95 3-Month Nonfinancial Commercial Paper (\% p.a.)

96 3-Month Treasury Bills, Secondary Market (\% p.a.)

97 6-Month Treasury Bills, Secondary Market (\% p.a.)

98 1-Year Treasury Bill Yield at Constant Maturity (\% p.a.)

99 5-Year Treasury Note Yield at Constant Maturity (\% p.a.)

100 10-Year Treasury Note Yield at Constant Maturity (\% p.a.)
Transformation

Source

LV

ISM

DLN

CNFBOARD

DLN

CNFBOARD

DLN

CNFBOARD

DLN

BEA

BEA

BEA

DLN

BEA

DLN

CENSUS

LN

CENSUS

LN

CENSUS

$\mathrm{LN}$

CENSUS

LN

CENSUS

LN

CENSUS

LN

CENSUS

LN

CENSUS

LN

CENSUS

LN

CENSUS

DLN

AUTHORS

DLN

AUTHORS

DLN

WSJ

DLN

FINTIMES

DLV

$\mathrm{S} \& \mathrm{P} / \mathrm{H}$

DLN

$\mathrm{S} \& \mathrm{P} / \mathrm{H}$

DLN

WSJ

DLN

FRB

DLN

FRB

DLN FRB

DLN FRB

DLN FRB

DLN FRB

DLV

FRB

DLV

FRB

DLV

FRB

DLV

FRB

DLV

FRB

DLV

FRB

DLV

FRB 
Transformation

101 Moody's Seasoned Aaa Corporate Bond Yield (\% p.a.)

102 Moody's Seasoned Baa Corporate Bond Yield (\% p.a.)

Yield Spreads

Eight Series Listed Below Minus the Federal Funds Rate

103 3-Month Nonfinancial Commercial Paper (\% per annum)

104 3-Month Treasury Bills, Secondary Market (\% p.a.)

105 6-Month Treasury Bills, Secondary Market (\% p.a.)

106 1-Year Treasury Bill Yield at Constant Maturity (\% p.a.)

107 5-Year Treasury Note Yield at Constant Maturity (\% p.a.)

108 10-Year Treasury Note Yield at Constant Maturity (\% p.a.)

109 Moody's Seasoned Aaa Corporate Bond Yield (\% p.a.)

110 Moody's Seasoned Baa Corporate Bond Yield (\% p.a.)

\section{Money and Credit Quantity Aggregates}

111 Money Stock: M1 (SA, Bil.\$)

112 Money Stock: M2 (SA, Bil.\$)

113 Money Stock: Institutional Money Funds (SA, Bil.\$)

114 Real Money Stock: M2 (SA, Bil.Chn.2000\$)

\section{St. Louis Adjusted Monetary Base}

115 Adj Monetary Base incl. Deposits to Satisfy Clearing Bal Contracts (SA, Bil.\$)

116 Adjusted Reserves of Depository Institutions (SA, Mil.\$)

117 Adjusted Nonborrowed Reserves of Depository Institutions (SA, Mil.\$)

118 Real Commercial and Industrial Loans Outstanding (SA, Mil.Chn.2000\$)

119 C\&I Loans in Bank Credit: All Commercial Banks (SA, Bil.\$)

120 Consumer Revolving Credit Outstanding (EOP, SA, Bil.\$)

121 Nonrevolving Consumer Credit Outstanding (EOP, SA, Bil.\$)

122 Ratio: Consumer Installment Credit to Personal Income (SA, \%)

Price Indices and Wages

123 PPI: Finished Goods (SA, $1982=100)$

124 PPI: Finished Consumer Goods (SA, $1982=100)$

125 PPI: Finished Goods: Capital Equipment (SA, $1982=100)$

126 PPI: Intermediate Materials, Supplies and Components (SA, $1982=100)$

127 PPI: Crude Materials for Further Processing (SA, $1982=100)$

128 PPI: Fuels and Related Products and Power (NSA, $1982=100$ )

129 PPI: Industrial Commodities Less Fuels \& Power (NSA, $1982=100$ )

130 Reuters/Jefferies CRB Futures Price Index: All Commodities $(1967=100)$

131 CPI-U: All Items (SA, 1982-84 = 100)

132 CPI-U: Apparel (SA, 1982-84 = 100)

133 CPI-U: Transportation (SA, 1982-84 = 100)

134 CPI-U: Medical Care (SA, 1982-84 = 100)

135 CPI-U: Housing (SA, 1982-84 = 100)

136 FRB Cleveland Median CPI (SAAR, \%chg)

137 CPI-U: Commodities (SA, 1982-84 = 100)

138 CPI-U: Durables (SA, 1982-84 = 100)
DLV

DLV

FRB

FRB

LV

LV

LV

LV

LV

LV

LV

LV

DLN

DLN

DLN

DLN

DLN

DLN

DLN

DLN

DLN

DLN

DLN

DLV

DLN

DLN

DLN

DLN

DLN

DLN

DLN

DLN

DLN

DLN

DLN

DLN

DLN

LV

DLN

DLN
FRB

FRB

FRB

FRB

FRB

FRB

FRB

FRB

FRB

FRB

FRB

FRB/BEA/H

FRBSTL

FRB

FRB

FRB/BEA/H

FRB

FRB

FRB

FRB/BEA/H

BLS

BLS

BLS

BLS

BLS

BLS

BLS

CRB

BLS

BLS

BLS

BLS

BLS

FRBCLV

BLS

BLS 


\section{Gavin and Kliesen}

Description

139 CPI-U: Services (SA, 1982-84 = 100)

140 CPI-U: All Items Less Food and Energy (SA, 1982-84 = 100)

141 CPI-U: All Items Less Food (SA, 1982-84 = 100)

142 CPI-U: All Items Less Shelter (SA, 1982-84 = 100)

143 CPI-U: All Items Less Medical Care (SA, 1982-84 = 100)

144 PCE: Chain Price Index $(S A, 2000=100)$

145 PCE: Durable Goods: Chain Price Index (SA, $2000=100$ )

146 PCE: Nondurable Goods: Chain Price Index (SA, $2000=100)$

147 PCE: Services: Chain Price Index (SA, $2000=100)$

148 PCE less Food \& Energy: Chain Price Index $(S A, 2000=100)$

149 Avg Hourly Earnings: Goods-producing Industries (SA, \$/Hr)

150 Avg Hourly Earnings: Construction (SA, \$/Hr)

151 Avg Hourly Earnings: Mfg (SA, \$/Hr)

152 New 1-Family Houses: Median Sales Price (\$)

153 NAR Median Sales Price: Existing 1-Family Homes, United States (\$)

\section{Miscellaneous}

154 ISM Mfg: Supplier Deliveries Index (SA, 50+ = Slowe)

155 University of Michigan: Inflation Expectations

156 University of Michigan: Consumer Expectations (NSA, Q1-66 = 100)

157 ISM Mfg: PMI Composite Index (SA, 50+ = Econ Expand)

NOTE:

\section{Nomenclature: By Transformation}

DLN: Change in logs, annualized

DLV: Change in levels

LV: Levels

\section{Nomenclature: By Data Source}

AUTHORS: Calculation by authors

BEA: Bureau of Economic Analysis

BLS: Bureau of Labor Statistics

CENSUS: U.S. Department of the Census

CB/CNFBOARD: The Conference Board

CRB: Commodity Research Bureau

DOL: Department of Labor

FINTIMES: Financial Times

FRB: Board of Governors of the Federal Reserve System

FRBCLV: Federal Reserve Bank of Cleveland

FRBSTL: Federal Reserve Bank of St. Louis

FRED: Federal Reserve Economic Data, Federal Reserve Bank of St. Louis

H: Haver Analytics

IP: Industrial Production

ISM: Institute for Supply Management

REALTOR: National Association of Realtors

S\&P: Standard \& Poor's

UMICH: University of Michigan Survey Research Center

WSJ: The Wall Street Journal

\begin{tabular}{cc} 
Transformation & Source \\
\hline DLN & BLS \\
DLN & BLS \\
DLN & BLS \\
DLN & BLS \\
DLN & BLS \\
DLN & BEA \\
DLN & BEA \\
DLN & BEA \\
DLN & BEA \\
DLN & BEA \\
DLN & BLS \\
DLN & BLS \\
DLN & BLS \\
DLN & CENSUS \\
DLN & REALTOR \\
& \\
LV & ISM \\
LV & UMICH/FRED \\
DLV & UMICH \\
LV & ISM
\end{tabular}

